\title{
Effects of two trimming methods of dairy cattle on concrete or rubber-covered slatted floors
}

\author{
W. Ouweltjes, ${ }^{* 1}$ M. Holzhauer,† P. P. J. van der Tol, ${ }^{* 2}$ and J. van der Werf* \\ ${ }^{*}$ Animal Sciences Group, PO Box 65, NL-8200 AB Lelystad, the Netherlands \\ †GD Animal Health Service Ltd., PO Box 9, NL-7400 AA Deventer, the Netherlands
}

\begin{abstract}
This study monitored claw health, claw conformation, locomotion, activity, and step traits of cows from a single dairy herd that were trimmed according to the standard Dutch method or with an alternative "concave" trimming method. Half of the cows were kept in a stall section with concrete slatted floors in the alleys. The other cows were kept in a pen within the same housing with an identical concrete slatted floor in the alleys, but with a rubber top layer. All experimental cows were kept in the same environment for at least 3 mo before and after trimming. It was hypothesized that trimming for more-concave soles (i.e., with 3 to $5 \mathrm{~mm}$ of sole dug out under the claw bone) was preferred to the standard Dutch trimming with flat sole surfaces for cows kept in stalls with soft alley floors. None of the claw health or locomotion traits differed for the trimming methods. No interactions were found between flooring and trimming method. Floor effects were significant for several traits. Cows on the rubber-topped floors had significantly fewer sole hemorrhages (prevalence of 22 vs. $48 \%$ in mo 3) and larger claws (claw length $76.1 \pm 5.0$ vs. $72.5 \pm$ $4.9 \mathrm{~mm}$; heel height $49.3 \pm 6.3$ vs. $46.0 \pm 6.4 \mathrm{~mm}$; claw diagonal $129 \pm 6.4$ vs. $125 \pm 6.9 \mathrm{~mm})$, spent more time standing in the alleys ( $55.4 \pm 2.8$ vs. $49.6 \pm 2.8 \%)$, and had higher activity $(61.0 \pm 3.7$ vs. $53.0 \pm 3.7$ steps $/ \mathrm{h})$. This suggests greater claw comfort on rubber flooring compared with concrete flooring. Kinetic patterns during claw-floor contact while walking were similar for all treatments. During the double-support (stance) phase, claw-floor contact area increased to a maximum in the first $30 \%$ of double-support phase time, remained more or less stable until $80 \%$ of double-support phase time, and sharply decreased as the animal pushed off as shown by the change in center of pressure. A gradual change of center of pressure in the medial direction dur-
\end{abstract}

Received July 17, 2008.

Accepted October 29, 2008.

${ }^{1}$ Corresponding author: Wijbrand.Ouweltjes@wur.nl

${ }^{2}$ Current address: Lely Industries NV, Weverskade 110, NL-3147 PA Maassluis, the Netherlands. ing double-support phase time was shown. The research hypothesis was rejected, but soft alley floors had subtle beneficial effects.

Key words: alley floor, trimming method, claw health and conformation, locomotion

\section{INTRODUCTION}

Several studies have reported that claw lesions and locomotor problems are widespread among dairy cattle (Somers, 2004; Holzhauer et al., 2006), especially in free stall herds (Sogstad et al., 2005). Claw disorders in dairy cows cause pain and are the main cause of impaired mobility in an environment that requires that cows move around for resources. Therefore, claw disorders are a serious animal welfare issue (Galindo and Broom, 2002). Prevalence of claw disorders is linked to the surfaces on which cows walk (Somers et al., 2003). Around $80 \%$ of Dutch dairy cows are housed in freestall barns, of which more than $90 \%$ are equipped with slatted concrete floors (Somers, 2004), and such floors were associated with suboptimal locomotion. Several investigations reported beneficial effects on locomotion when concrete floors were equipped with rubber walking surfaces (Rushen and de Passillé, 2006; Flower et al., 2007). Tucker et al. (2006) showed that cows prefer soft walking surfaces over hard concrete, and there is growing interest among farmers to apply rubber top layers in their barns. Although soft flooring decreases the environmental challenge for mechanical overload, it is unlikely that it will prevent all claw lesions. Boyle et al. (2007) argue that housing comfort regarding claws was determined both by flooring and free stalls. Correspondingly, Kremer et al. (2007) and Vanegas et al. (2006) reported no significant improvement of claw health through soft flooring.

Preventive hoof trimming is a common practice on dairy farms (Manske et al., 2002). In the Netherlands, regardless of their housing conditions, cows are trimmed according to guidelines developed by Toussaint Raven (1989). This so-called Dutch method was developed at a time when soft flooring was uncommon and cows walked on pasture more often than they do today. With this 
trimming method the weight-bearing surface of the sole is balanced over the lateral and medial claws. Pressure distribution measurements showed that soft and sensitive areas of the sole are loaded relatively heavily after trimming (Van der Tol et al., 2004). From a functional morphological perspective, soles with a weight-bearing wall combined with a bulb that bears only a minor part of the weight seem a better option (Van der Tol, 2004; Nuss and Paulus, 2006). Studies (Kremer et al., 2007; Telezhenko, 2007) showed that soft top layers on walking floors resulted in lower horn growth and wear and increased claw size. Telezhenko (2007) reported that rubber walking surfaces preserved sole concavity.

Given the unfavorable mechanical loading pattern of standard trimming, the changed claw conformation, and a lack of clear improvement of claw health for cows kept on soft floors, the question is whether the trimming method should be modified for these flooring conditions. The hypothesis was that on softer floors, soles trimmed to be more concave are preferred over standard trimmed soles, and that effects will be visible within 3 mo. The aim was to evaluate the effects of the standard Dutch trimming method versus an alternative trimming method in combination with a concrete or rubber-covered slatted floor on claw health, claw conformation, locomotion, and pressure distribution.

\section{MATERIALS AND METHODS}

\section{Animals and Housing Conditions}

The study was carried out at research farm "De Waiboerhoeve" of the Animal Sciences Group in Lelystad, the Netherlands. The farm had a 400-cow Holstein herd with year-around calving. All dry cows at the farm were kept in a pen with concrete slatted alleys, and claws were trimmed at dry off according to the Dutch method following standard management procedures. After calving, cows entered 1 of 5 milking groups randomly [4 automatic milking system (AMS)-milked groups and a parlor-milked group]. The experimental cows $(\mathrm{n}=72)$ were selected from 2 groups of about 60 animals kept in 2 adjacent sections of free stalls with mirror-image layouts under the same roof. The 2 different sections of free stalls had different types of floor (see treatments), but all other housing and management conditions were similar. Treatments consisted of a combination of floor and trimming method (see treatments). All experimental cows were kept in their environment from calving onward. Water and a partially mixed ration were available ad libitum; ration formulation was according to Dutch nutritional guidelines. The cows were milked by AMS (Astronaut A2, Lely Industries, Maassluis, the Netherlands) and received 1 to $6 \mathrm{~kg}$ of concentrates daily during milking, depending on their production level. Production data of the AMS (date and time of visit, milk yield) were recorded in the herd management system and used for descriptive analysis.

The cows entered the experiment 3 to 4 mo after calving, when they were about to be trimmed according to standard management procedures. Criteria for inclusion were that the animals were clinically healthy and had a locomotion score of 2 or less on the 5-point scale described by Manson and Leaver (1988); that is, they should not be lame and the claws had enough horn for trimming by either of the 2 methods. During the experiment, cows were not treated for any disease that affects locomotor behavior. However, when cows were diagnosed with severe lameness (i.e., gait score $>3.5$ ) or another serious illness they were removed from the study. Seven cows were removed before the end of the observation period. Three of those had udder health problems, 2 had undefined disease problems, 1 cow died, and 1 had claw problems. Data from these animals were not used for statistical analysis. The study was approved by the institute's (ASG-WUR, Lelystad) Animal Care and Ethics Committee. The animals entered the study between May 23 and June 21, 2006, on 5 different days and were followed for a period of 3 mo each. Parities of the animals ranged from 1 to 4 . Every $2 \mathrm{wk}$ a footbath containing, alternately, a solution of formalin or formalin-copper sulfate, was placed in their path for $2 \mathrm{~d}$.

\section{Treatments}

The 2 free-stall sections used for the experiment had either a slatted concrete floor (SC; $\mathrm{n}=14$ heifers and $\mathrm{n}=21 \mathrm{cows})$ or an identical slatted floor with rubber walking surfaces (SR; $\mathrm{n}=12$ heifers and 18 cows). Both prefabricated floors were provided by Concrelit Betonindustrie (Steenwijk, the Netherlands), and the rubber coating was manufactured by Animat (SaintÉlie d'Orford, Canada). Both floors were cleaned automatically every $45 \mathrm{~min}$ by a manure scraper (De Boer, Leeuwarden, the Netherlands). One of 2 trimming methods was randomly assigned to the animals, but a distinction was made between heifers and cows to prevent an unbalanced distribution of cows and heifers over treatments. The 2 trimming methods standard (ST, n $=14$ heifers and 19 cows) or hollow (HO; n $=12$ heifers and 20 cows) are illustrated in Figure 1. Before the experiment started the claw trimmer (who trimmed all claws throughout the study) was trained in both methods. Experimental groups (same floor and trimming method) were matched for parity and date of entering the experiment. 


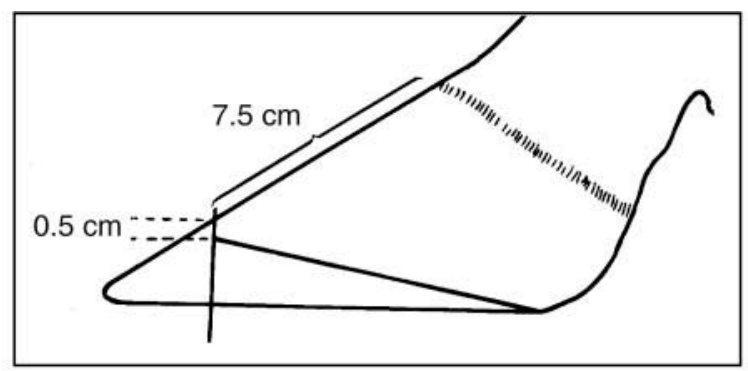

Inner claw Outer claw

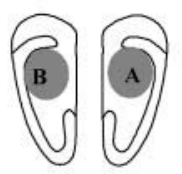

Standard trimming

Make the medial claw $7.5 \mathrm{~cm}$ long

Make the toe $0.5 \mathrm{~cm}$ thick

Save height in the bulb area

Make the lateral claw same length and height as medial claw (if possible)

Make the soles flat

Figure 1. Outline of preventive trimming methods.

\section{Measurements}

The cows were monitored for claw health, claw dimensions, locomotion, and claw pressure distributions at trimming and 1 and 3 mo later. Claw health was recorded for each hind leg by scoring the presence of digital dermatitis, interdigital dermatitis, sole hemorrhages, white line defects, sole ulcer, tyloma (also known as interdigital hyperplasia), and interdigital phlegmon according to Holzhauer (2006). Because white line defects, sole ulcer, and tyloma were rarely recorded, these disorders were grouped together for analysis in the category other claw disease. Interdigital phlegmon was not observed. If present, digital dermatitis, interdigital dermatitis, and sole hemorrhages were scored on a scale from 1 (mild) to 3 (severe); the other disorders were scored as either present (1) or absent (0). For the measurements after 1 and 3 mo, claws were cleaned and a minimum of sole horn, just enough to visually score horn lesions, was removed. Lesions were scored by experienced personnel.

Claw dimensions were assessed by measuring claw angle, claw length, heel height, claw diagonal, and claw width for both medial and lateral hind claws as described by Somers et al. (2005), and outlined in Figure 2 (adapted from their paper with permission). Horn growth and wear of medial and lateral hind claws were measured as described. After claw disorders and claw dimensions were recorded, and before cows were returned to their free-stall sections, the cows were filmed while walking on the same strip of slatted concrete floor
Hollow trimming

Make the medial claw $7.5 \mathrm{~cm}$ long

Make the toe $0.5 \mathrm{~cm}$ thick

Save height in the bulb area

Make the lateral claw same length as medial claw (if possible), height difference up to 5 mm may remain

Make sole models according to the above: grey areas A and B can be dug out 3 to $5 \mathrm{~mm}$ if the sole is thick enough

next to their free-stall sections. Scoring of all films was performed by the first author (WO). Gait scores were recorded according to Manson and Leaver (1988) with 9 half-point classes in the range from 1 (healthy) to 5 (extremely lame). Midway through the experiment, from July 18 until August 14, 2006, activity data were obtained with IceTag activity sensors (version 2.003, IceRobotics Ltd., Roslin, Midlothian, UK). The sensors recorded the percentage of time a cow was lying, standing or active and the number of steps per minute. Because 16 sensors were available, 4 different animals in each treatment group were equipped twice weekly with a sensor for 3 to $4 \mathrm{~d}$. Thus, after 2 wk data were obtained from 64 of the experimental animals, and in the next 2 wk the same animals were measured again in the same order.

Claw-floor interactions during locomotion were captured by means of a pressure distribution (PD) plate (footscan 2D-box, RsScan International, Olen, Belgium). The PD plate had a 976- $\times 325-\mathrm{mm}$ measuring surface containing 8,192 conductive pressure-sensitive polymer sensors that were each $5 \times 7.6 \mathrm{~mm}$ in size. The PD plate was embedded such that the top surface of the PD plate was at the same height as the surrounding walkway. To protect the PD plate the walkway was covered with a 2-mm-thick rubber mat. This minimized any visual disturbance that might be created by the equipment (Van der Tol, 2004). The cows were driven down the walkway and if cows ran, stood still, or slipped, those data were discarded. The PD plate was connected to a computer that recorded the 

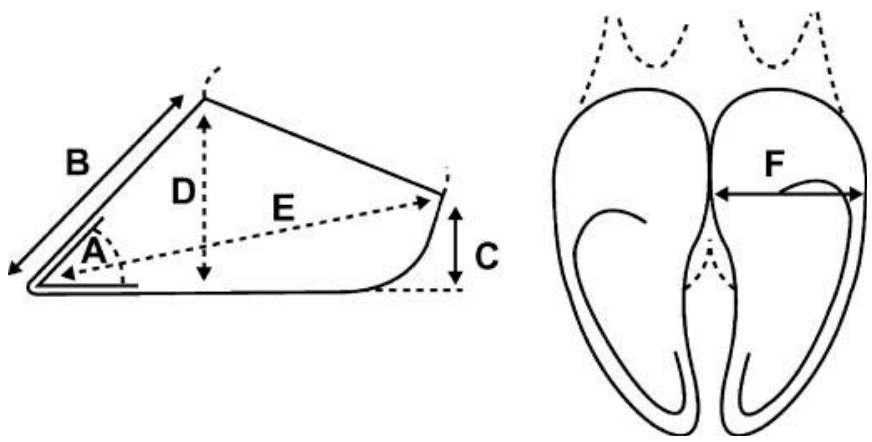

Figure 2. Illustration of the claw traits measured on the hind claws to describe shape (adapted from Somers et al., 2005): A = claw angle; $\mathrm{B}=$ claw length; $\mathrm{C}=$ heel height; $\mathrm{D}=$ claw height (not measured in this study); $\mathrm{E}=$ claw diagonal; $\mathrm{F}=$ claw width.

pressure measurements for later analysis. All pressures above zero were measured and stored. Body weights were measured by weighing platforms in the AMS, and mean individual BW were calculated for each animal for experimental mo 0,1 , and 3.

\section{Data Processing}

Pressure distribution data were processed to perform statistical analysis. First, for each cow and hind leg, 1 recording per measurement session was selected for which the footscan software indicated no irregularities; the other hoof strike data obtained were not used for analysis. The selected hoof strike data were exported in ASCII-format and saved in Excel format (Microsoft Corp., Redmond, WA) for processing purposes. For each scan the number of touched sensors, total vertical force, maximum force for an individual sensor, and coordinates of center of pressure (COP) were calculated. Also, minimum and maximum $\mathrm{x}$ - and y-coordinates per hoof strike were calculated to express COP in terms of percentages of the range of possible $\mathrm{x}$ and $\mathrm{y}$ values. From these data for each hoof strike relative values (as a percentage of hoof strike average) for claw-floor contact area (CA), total vertical force (Fsum), maximum vertical force per sensor $(\mathbf{F m a x})$, and center of pressure in a lateromedial direction $(\mathbf{C O P x})$ and in a craniocaudal direction (COPy) (as a percentage of maximum value per hoof strike) per percentage of total double-support phase time were calculated. In a complete 2-step cycle, all feet are in contact with the ground at the same time for about $25 \%$ of the time. This part of the cycle is called the double-support phase. Because COPx for the left and right foot develop in opposite directions, the values for COPx of the right hind legs were reversed. Furthermore, per footprint double-support phase time average claw-floor contact area (CAmean, $\left.\mathrm{cm}^{2}\right)$, corrected mean vertical force (Fmean), and double-sup- port phase time (StT, ms) were calculated. Registered vertical forces were precorrected because preliminary analysis revealed large and unexplainable level differences between measurement sessions for this variable. These differences did not affect relative patterns during double-support phase time. Correction factors were ratios of the average BW of the animals measured and the average maximum forces for each measurement session. Double-support phase time was determined from first recorded claw-floor contact to final contact.

\section{Statistical Procedure}

Claw disorders were analyzed with Genstat statistical package (GenStat 9.2, 2007, VSN International, Hemel Hempstead, UK) with the following GLM model:

$$
Y_{i j k l m n}=\mu+F_{i}+T_{j}+F_{i} \times T_{j}+B l_{k}+C_{k l}+O_{m}+e_{i j k l m n},
$$

where $Y_{i j k l m n}$ is the variable recorded for floor $i$, trimming method $j$, block of entry $k$, cow $l$ within block $k$, observer $m$, and repeated observation $n ; \mu$ is the overall mean; $F_{i}$ is the type of floor on which a cow was kept (SC, SR); $T_{j}$ represents trimming method (ST, HO); $B l_{k}$ represents the date of entry $(\mathrm{k}=1,5) ; C_{k l}$ is the individual animal effect $(1=1,65)$; and $O_{m}$ indicates the observer $(\mathrm{m}=1,3)$ performing the measurements; $B l_{k}, C_{k l}, O_{m}$, and the error term are the random components of the model. Data were analyzed separately for measurements at d 0 and after 1 and 3 mo with the above model, but data for mo 1 and 3 were analyzed with previous lesion scores as covariate added to the model. Measurements on left and right hind legs were treated as repeated observations on the same animal, and all lesion scores were analyzed as digital variables.

Claw dimensions (claw angle, claw length, heel height, diagonal, and width) and claw growth and wear were analyzed with REML type analysis with Genstat with the following model:

$$
Y_{i j k l m n}=\mu+F_{i}+T_{j}+C l_{k}+b_{1} \times M_{l}+b_{2} \times M_{l}^{2}+R_{m}+e_{i j k l m n},
$$

where $Y_{i j k l m n}$ is the variable recorded for floor $i$, trimming method $j$, claw $k$, measurement $l$, random effects $m$, and repeated observation $n ; \mu$ is the overall mean; $F_{i}$ is the type of floor on which a cow was kept (SC, $\mathrm{SR}) ; T_{j}$ represents trimming method (ST, $\mathrm{HO}$ ); $C l_{k}$ is medial or lateral claw; and $M_{l}$ is the measurement $(0$, 1 , or $3 \mathrm{mo}$ ). All interactions between fixed effects were tested and remained in the model when significant; $R_{m}$ indicates random effects for animal (1 to 65), leg within animal (left or right) and observer $(\mathrm{m}=1,3)$ performing the measurements. Values for claw angle, 
length, and width were log-transformed for analysis because the error terms otherwise were not normally distributed.

Gait scores were analyzed with Genstat REML. The data were analyzed for each measurement separately and for all measurements simultaneously with correction for time of measurement. Furthermore, for measurements at mo 1 and 3 , analyses were done with a correction for gait score at d 0 and for measurements at mo 3 with correction for gait score at mo 1 . The model was similar to that used for claw dimensions, except that claw was excluded and animal was the only random effect.

The data from the IceTag sensors (percentages of time standing, lying, active, and number of steps) were analyzed with GLMM in Genstat. Although data could be retrieved per second, data were grouped per hour for final analysis. Fixed effects in the model were floor, trimming method, and interaction of floor and trimming method. Random effects corrected for block, hour, animal, day, and sensor.

Development of PD parameters during stance time was analyzed with ASREML (Gilmour et al., 2006) with the following model:

$$
\begin{aligned}
Y_{i j k l m n o}= & +M_{i} \times F_{j} \times T_{k}+P t_{l}+f\left(P t_{i j k l}\right) \\
& +D_{m}+R_{n}+e_{i j k l m n o}
\end{aligned}
$$

where $Y_{i j k l m n o}$ is the variable recorded for measurement number $i$, floor $j$, trimming method $k$, percentage of time $l$, measurement date $m$, cow $n$, and repeated observation $o ; \mu$ is the overall mean; $M_{i}$ represents measurement number $(0,1$ or $3 \mathrm{mo}) ; F_{j}$ is the type of floor on which a cow was kept (SC, SR); $T_{k}$ represents trimming method (ST, HO); $P t_{l}$ represents percentage of time during the hoof strike; $f\left(P t_{i j k l}\right)$ is a spline describing the effects percentage of time per measurement and treatment; $D_{m}$ represents the date of measurement $(\mathrm{m}=1,14)$; and $R_{n}$ is the individual animal effect $(\mathrm{n}=1,65) ; D_{m}, R_{n}$, and the error term were the random components of the model. Step parameters per hoof strike derived from PD data were analyzed with a similar model (without terms for percentage of time).

\section{RESULTS}

\section{Claw Disorders}

Significance levels of the fixed effects in the model are in Table 1. Correction of observations at mo 1 for observations at d 0 and correction of observations at mo 3 for observations at mo 1 yielded similar results and are not presented. Adding parity (heifer vs. cow) to the model for claw disorders yielded very similar results. Differences between heifers and cows were only significant for sole hemorrhages at $\mathrm{d} 0$, with a greater predicted mean prevalence for heifers than for cows $(87$ vs. $57 \%$ ). Presence of digital dermatitis or interdigital dermatitis at d 0 significantly increased the likelihood of presence of these disorders later on, whereas this was not found for the other claw disorders. Floor by trimming interaction was significant for digital dermatitis at mo 3: predicted means for treatments were 0.11 for SC floor and ST trimming, 0.02 for SC floor and HO trimming, 0.03 for SR floor and ST trimming, and 0.13 for SR floor and $\mathrm{HO}$ trimming. These treatment differences were similar to those present at d 0 , and probably do not indicate true interaction. Predicted mean prevalence of sole hemorrhages at mo 1 and 3 was significantly higher on SC (48\% on both occasions) than on SR (16 and $22 \%$, respectively), and on both floors, the prevalence of sole hemorrhages decreased after $\mathrm{d}$ 0. Apart from the results for digital dermatitis at mo 3, there was no evidence for an effect of trimming methods or interaction of trimming method and flooring on the prevalence of claw disorders.

\section{Claw Dimensions}

Significance levels of the fixed effects that remained in the model for claw dimensions are presented in Table 2. None of the claw dimensions was influenced by trimming method, although some interactions with trimming method were significant. The significance of time of measurement indicated that most of the claw dimensions changed during the experiment. The significance of claw (except for claw length) indicated that there were differences between medial and lateral claws in claw dimensions. The predicted means for claw dimensions for each measurement for medial and lateral claws on both floors are in Figure 3. Lateral claws had smaller claw angles than medial claws $(P=0.007)$, and the claw angles became smaller on the SR floor than on the SC floor because of a larger decrease after trimming on the SR floor $(P<0.001)$. Claw length was longer for the SR floor than for the SC floor $(P<0.001)$. Heel height and claw diagonal were larger for lateral claws $(P<0.001)$ on both floors, and increased more during the experiment on the SR floor $(P=0.0321$ and $P<$ 0.001 respectively). Claw width was similar for both floors, but lateral claws had larger values $(P<0.001)$ and a larger increase $(P<0.001)$ than medial claws. An increase in the distance from the coronary band to the growth marker was larger for lateral than for medial claws $(P=0.006)$ and was larger for the SC than the SR floor $(P<0.001)$. Decrease of distance from the growth marker to the sole was similar for medial and 
Table 1. Incidence of claw disorders and $P$-values of flooring and trimming method ${ }^{1}$

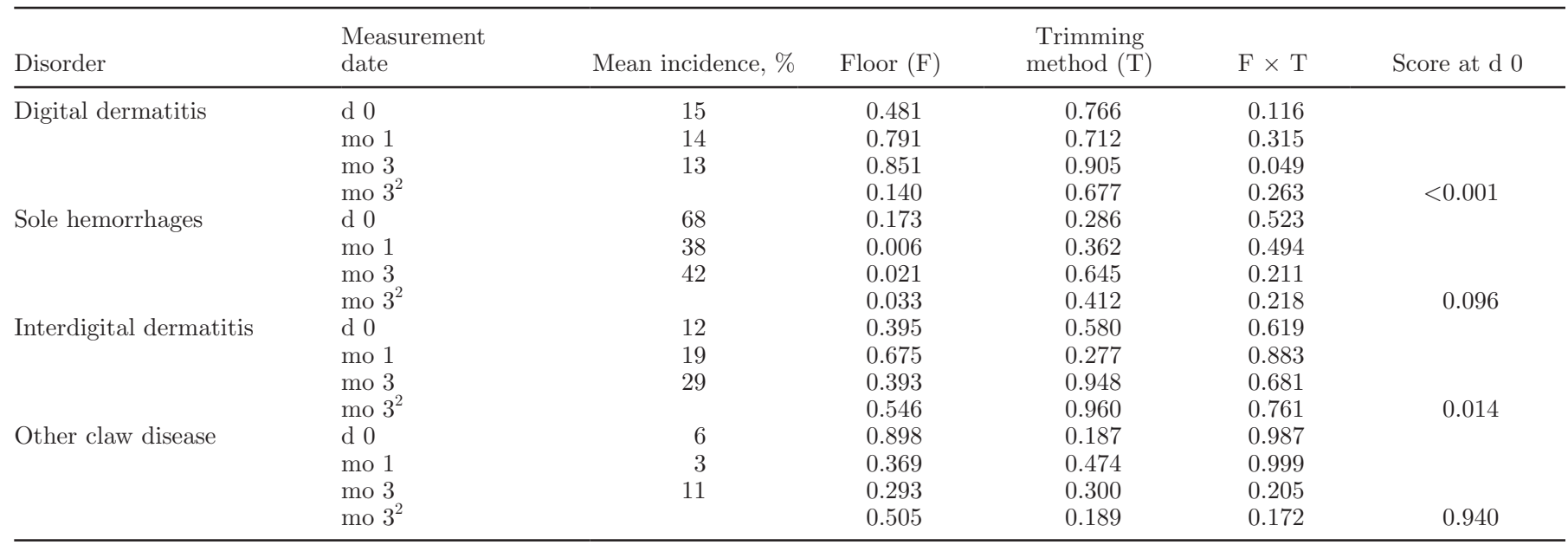

${ }^{1} P<0.05$ are significant.

${ }^{2}$ Model with correction for score at d 0 .

lateral claws, but was larger for the SC than SR floor $(P<0.001)$.

\section{Gait Scores}

Gait scores at d $0(1.7 \pm 0.6), 1$ mo $(1.6 \pm 0.6), 3$ mo $(1.7 \pm 0.6)$, and overall gait scores corrected for measurement $(1.7 \pm 0.4)$ were not significantly influenced by floor or trimming method, indicating that gait scores remained stable throughout the experiment. Analysis of 1-mo gait scores corrected for gait score at d 0 and of 3-mo gait scores corrected for gait score at d 0 or at 1 mo revealed similar results. The maximum gait score was 4 .

\section{Activity Measures}

Activity traits were not significantly different between trimming methods, and no interactions of flooring and trimming method were found. Floor effects indicated there was more standing $(55.4 \pm 2.8$ vs. $49.6 \pm 2.8 \%$; $P<0.001)$, more activity $(4.9 \pm 0.7$ vs. $4.4 \pm 0.7 \%$; $P<0.001)$, and more steps $(61 \pm 3.7$ vs. $53 \pm 3.7 ; P$ $<0.001)$ for the cows on the SR floor compared with cows on the SC floor. Yet, the percentage of lying time was greater for cows on SC than SR $(44.8 \pm 3.9$ vs. $38.2 \pm 3.0 ; P<0.014)$. The IceTag data were linked to the scores for sole hemorrhages. Although these data were not statistically analyzed, cows without sole hemorrhages at mo 1 and 3 spent more time standing in the alleys (54 vs. 50\%) and made more steps (60 vs. 54) than the animals with sole hemorrhages. Most animals with sole hemorrhages were from the SC floor, and cows on this floor generally stood and stepped less.
The greater activity of cows on the SR floor was reflected in shorter milking intervals for SR floor with ST trimming and SR floor with $\mathrm{HO}$ trimming $(465 \pm 70$ and $479 \pm 77 \mathrm{~min}$ ) than for SC floor with ST trimming and SC floor with HO trimming (504 \pm 68 and $519 \pm$ $81 \mathrm{~min})$. Despite that, average daily yields $(33.0 \pm 4.7$, $33.1 \pm 5.6,34.4 \pm 5.1$, and $33.8 \pm 5.6 \mathrm{~kg} / \mathrm{d}$ for $\mathrm{SR}+\mathrm{ST}$, $\mathrm{SR}+\mathrm{HO}, \mathrm{SC}+\mathrm{ST}$, and $\mathrm{SC}+\mathrm{HO}$ ) were not significantly different between treatment groups.

\section{Step Measures}

Significance levels of fixed effects for development of step measures during double-support phase time are summarized in Table 3. Because these variables were expressed as percentage of mean values, means are omitted. All variables changed significantly during the double-support phase. Residual variance of COPx was larger than that of COPy (63.6 vs. 43.5). Predicted patterns for all traits were calculated with the full model and compared; this revealed that the patterns were not different for the 3 measurements or treatment classes, despite the significance of measurement date $(0,1$, or $3 \mathrm{mo})$ by floor type, measurement date by trimming method, and measurement date by floor type by trimming method interactions for these traits. Therefore, overall patterns are presented in Figure 4. Claw-floor contact area increased to a maximum in the first $30 \%$ of double-support phase time, remained more or less stable until $80 \%$ of double-support phase time, and decreased sharply until push off. Total vertical force showed a similar pattern. Maximum vertical force per sensor had low values only in the early and late stages of a step. The COP for hind legs slowly shifted 


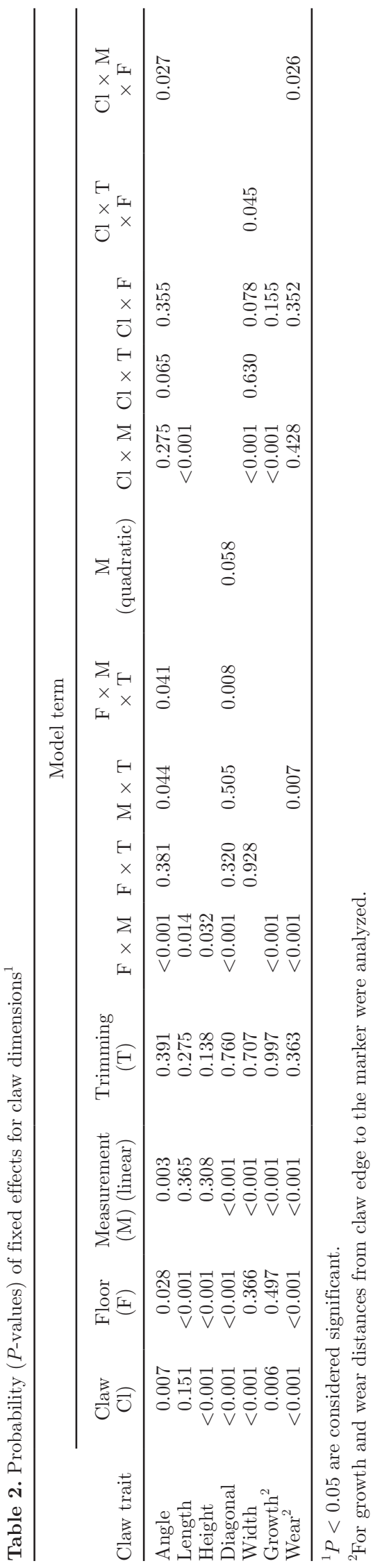

in medial and forward direction. Weight was clearly shifted to the front part of the claw in the last $20 \%$ of double-support phase time. Predicted mean values and significance of effects for step measures are summarized in Table 4. For CAmean differences between SR and SC floors (30.2 \pm 1.8 and $36.0 \pm 1.7 \mathrm{~cm}^{2}$, respectively) and trimming methods $\left(31.9 \pm 1.8\right.$ and $34.2 \pm 1.7 \mathrm{~cm}^{2}$ for HO and ST, respectively) were significant, and both these factors interacted with measurement number. The floor type by trimming method interactions were not significant for any of these traits, indicating that flooring did not affect the effects of trimming. Standing time was not affected by treatment factors and did not change over time. The estimates for CAmean for treatment groups are presented in Figure 5. This figure shows that CAmean on SC quickly increased after trimming for both trimming methods. Differences between floors increased toward the end of the experiment. Hollow trimming resulted in smaller CAmean values at $\mathrm{d}$ $0\left(26.3 \pm 2.9\right.$ vs. $\left.31.9 \pm 2.9 \mathrm{~cm}^{2}\right)$, but the difference with standard trimming diminished within 1 mo after trimming and had completely disappeared at the end of the experiment for both floors. Predicted means for Fmean for treatment groups for the 3 measurement months are presented in Figure 6. Figures for the third measurement were clearly different from the other 2 measurements. Only for this measurement was there a substantial difference in Fmean between both floor types $(495 \pm 17$ for $\mathrm{SC}$ vs. $350 \pm 19$ for SR); it is remarkable that both Fmean and CAmean $(39.6 \pm 2.9$ for $\mathrm{SC}$ vs. $28.7 \pm 3.0$ for $\mathrm{SR}$ ) were lower for the SR floor.

\section{DISCUSSION}

The hypothesis was that the standard Dutch flat trimming method provides suboptimal results compared with the alternative hollow trimming on soft floors. This was based on 2 phenomena. First, results from PD plate measurements showed that the sole area under the claw bone was loaded relatively heavily after trimming by the Dutch method (Van der Tol et al., 2004). Second, some studies have indicated that soft floors result in lesser wear and larger claws (Kremer et al., 2007; Telezhenko, 2007). Removal of horn in the sole area under the claw bone was expected to reduce the load on this sensitive area, and thus improve locomotion. On hard and more abrasive floors the smaller claw floor contact area might eventually cause increased wear and result in thinner soles, but on soft floors, this method was expected to have beneficial effects. The hypothesis was not supported by our findings. None of the traits studied showed an interaction of flooring and trimming method. Nevertheless, effects 
Claw angle

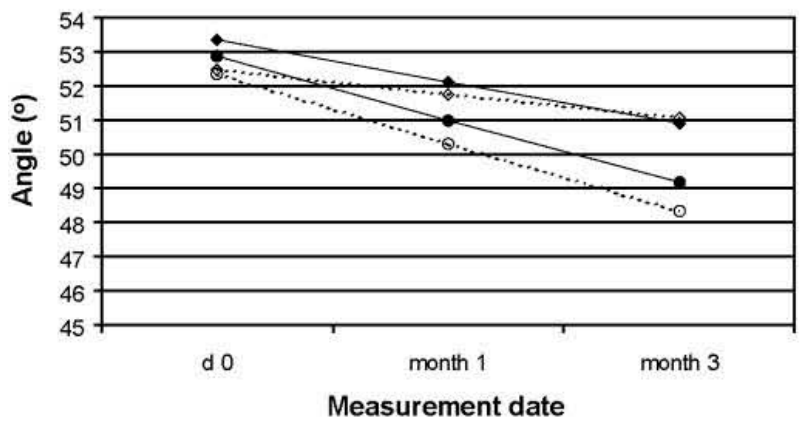

Heel height

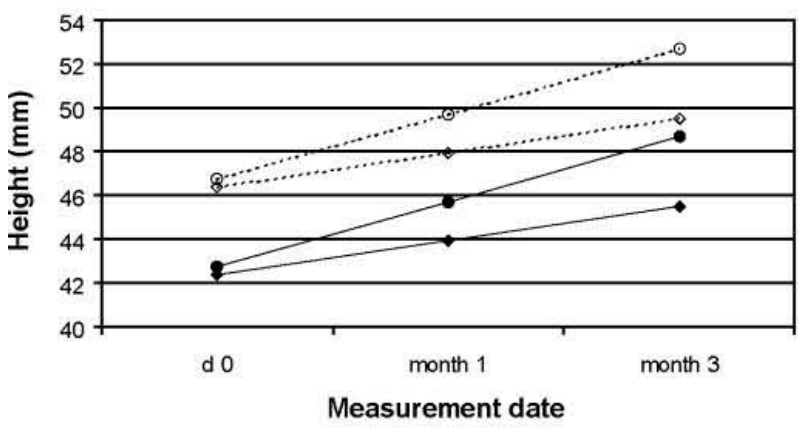

Claw width

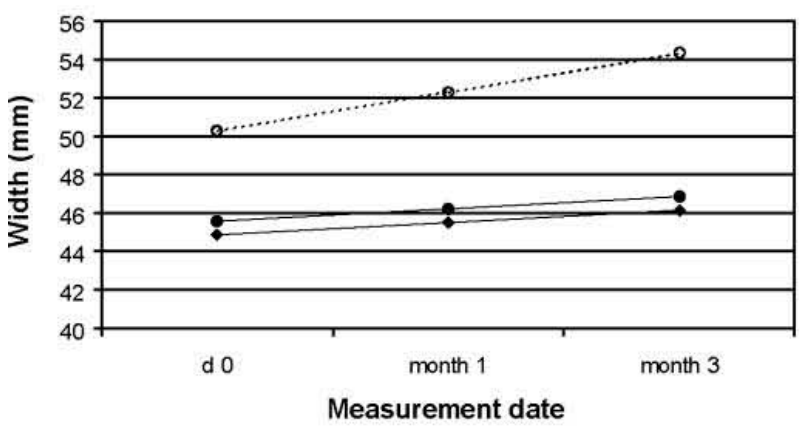

Distance from marker (wear)

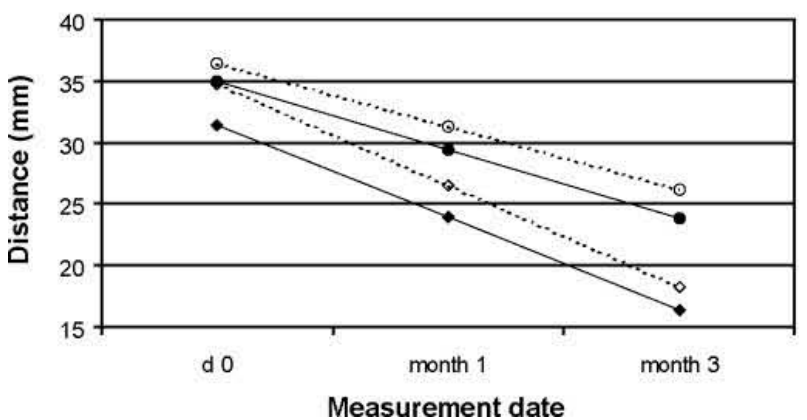

Claw length

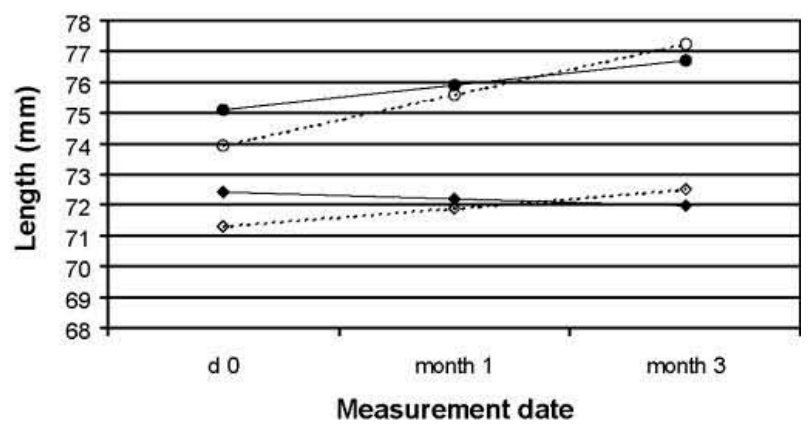

Claw diagonal

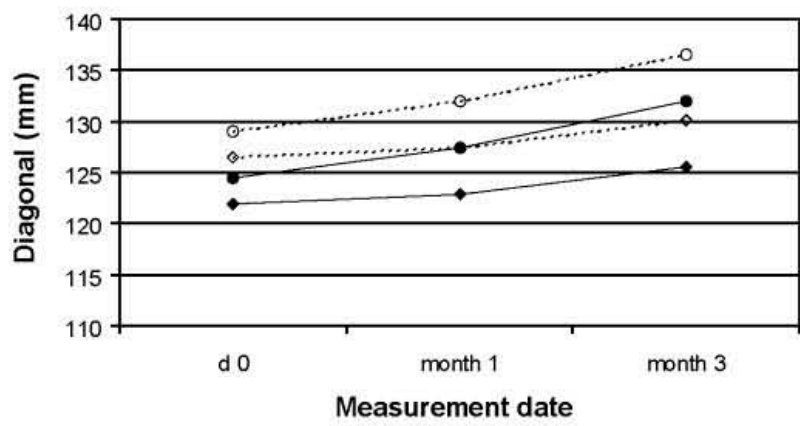

Distance to marker (growth)

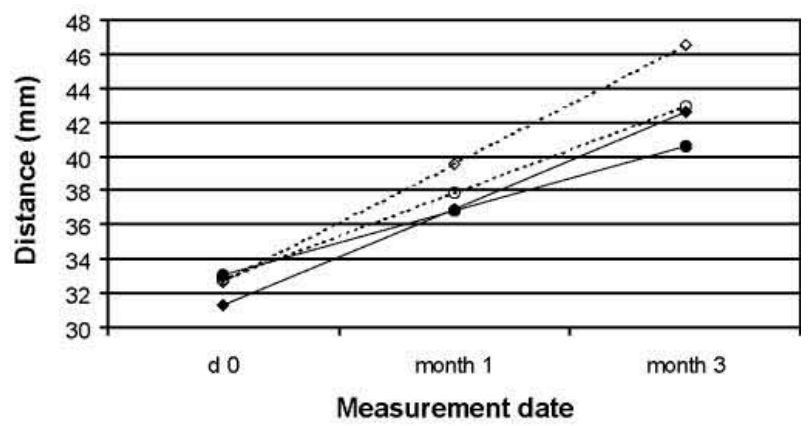

$\longrightarrow$ slatted concrete, medial claw

$\ldots \otimes$ slatted concrete, lateral claw

- slatted rubber, medial claw

...๑... slatted rubber, lateral claw

Figure 3. Development of claw shape per floor and claw. 


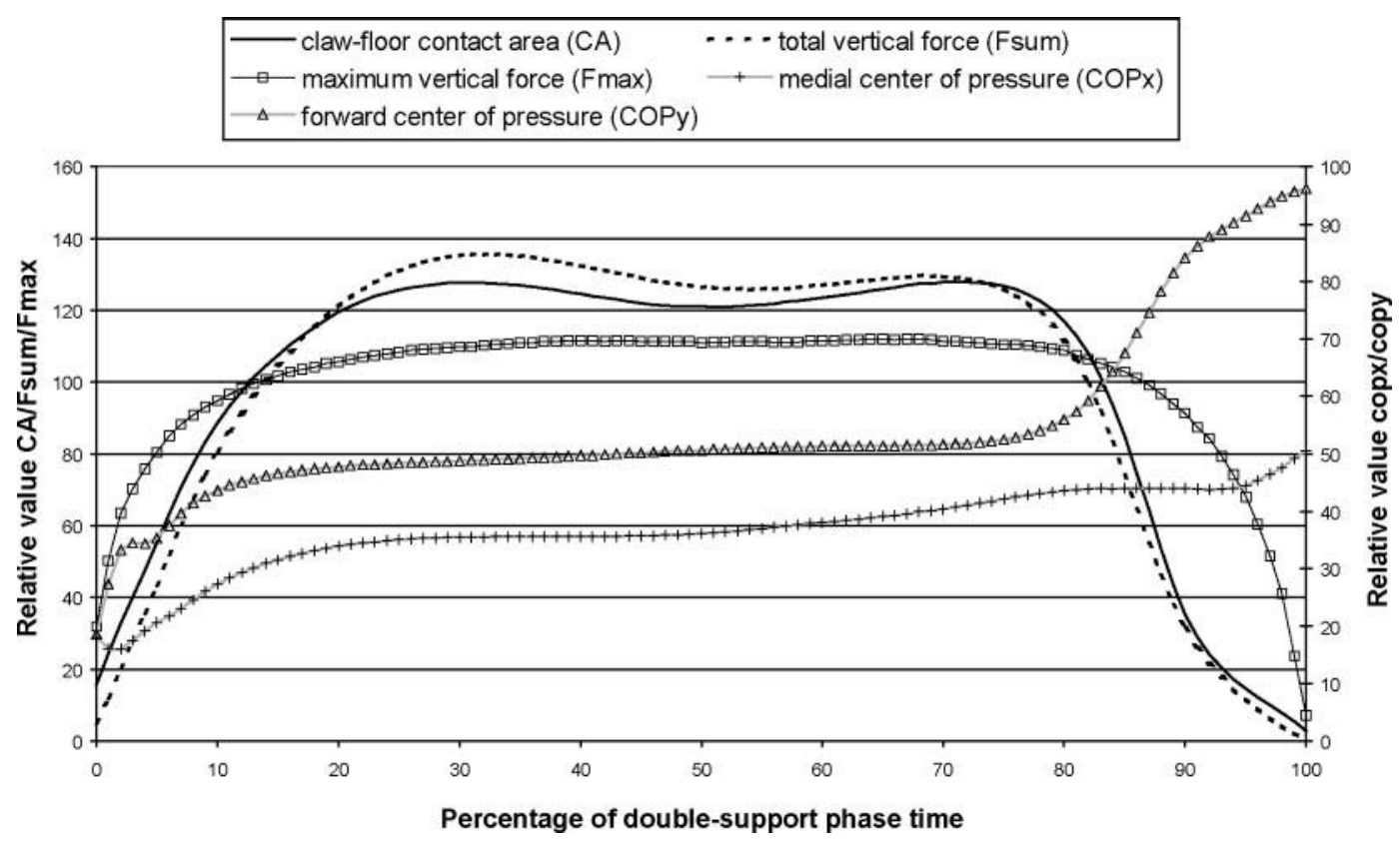

Figure 4. Development of step characteristics during the double-support phase (stance) time.

of trimming method were significant for claw-floor contact area. Differences in CAmean between trimming methods quickly disappeared after trimming. There were no indications that alternative trimming on hard floors increased horn wear. It remains unclear which trimming method is optimal under the given conditions in the long term. Nuss and Paulus (2006) argued that the standard Dutch trimming method can result in excessive thinning of soles of lateral claws. Thinning soles could be exacerbated by paring out the soles in the areas A and B (Figure 1) if not done correctly, but this was not the case with our alternative method. Nuss and Paulus (2006) suggest that medial claw soles should be $8 \mathrm{~mm}$ thick instead of $5 \mathrm{~mm}$. All animals in our experiment were kept in a pen with a concrete slatted floor before calving and were trimmed according to the standard Dutch method at drying off. Because claw conformation changes only gradually, the claws of the experimental cows on the SR floor may not have been representative of claws of cows kept on soft floors for a longer period. If cows are kept on soft flooring for a longer time and sole concavity can be maintained during trimming instead of created by paring out soles, the results might have been different. Although claw dimensions were not measured before trimming, the larger claw length after trimming for the cows on SR floor suggests that flooring affected the claw shape of the cows at the start of the study. Therefore, these cows, to some extent, do represent animals kept on different floor systems. Our results suggest that differences between hard and soft flooring are more relevant for claw health and conformation and locomotor behavior than differences between the trimming methods we applied, although only sole hemorrhages occurred significantly less on the soft floor. Fjeldaas et al. (2006) reported that routine claw trimming did not improve claw health

Table 3. Probability ( $P$-values) for development of claw-floor contact area, total vertical force, maximum vertical force per sensor, and center of pressure during claw-floor contact time ${ }^{1}$

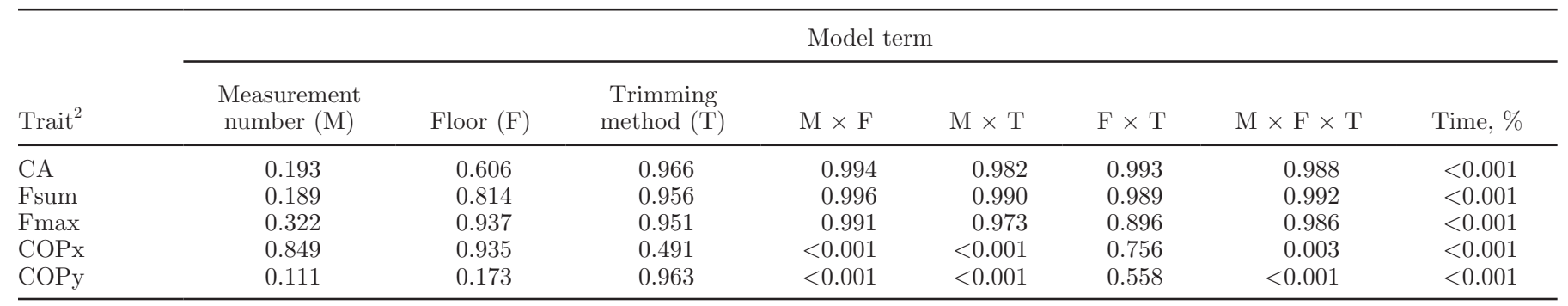

${ }^{1} P<0.05$ are significant.

${ }^{2} \mathrm{CA}=$ claw-floor contact area; Fsum $=$ total vertical force; Fmax $=$ maximum vertical force per sensor; COPx $=$ center of pressure in lateromedial direction; $\mathrm{COPy}=$ center of pressure in craniocaudal direction. 
Table 4. Predicted mean values for step characteristics and $P$-values for model factors ${ }^{1}$

\begin{tabular}{|c|c|c|c|c|c|c|c|c|}
\hline Trait $^{2}$ & Mean $\pm \mathrm{SE}$ & $\begin{array}{l}\text { Measurement } \\
\text { number (M) }\end{array}$ & Floor $(\mathrm{F})$ & $\begin{array}{l}\text { Trimming } \\
\text { method }(\mathrm{T})\end{array}$ & $\mathrm{M} \times \mathrm{F}$ & $\mathrm{M} \times \mathrm{T}$ & $\mathrm{F} \times \mathrm{T}$ & $\mathrm{M} \times \mathrm{F} \times \mathrm{T}$ \\
\hline CAmean $\left(\mathrm{cm}^{2}\right)$ & $33.1 \pm 1.7$ & 0.178 & $<0.001$ & 0.017 & $<0.001$ & $<0.001$ & 0.565 & 0.791 \\
\hline Fmean $^{3}$ & $413.5 \pm 6.5$ & 0.002 & $<0.001$ & 0.782 & $<0.001$ & 0.016 & 0.500 & 0.944 \\
\hline
\end{tabular}

${ }^{1} P<0.05$ are significant.

${ }^{2}$ CAmean $=$ average claw-floor contact area Fmean $=$ corrected mean vertical force; $\mathrm{StT}=$ double-support phase (stance) time.

${ }^{3}$ Due to correction, Fmean is a unitless variable.

and claw shape in free stalls, but a preventive effect was found for claw disorders in tie stalls, suggesting that the Norwegian claw trimming method was not adjusted to free-stall housing and flooring. Manske et al. (2002) reported beneficial effects of trimming on claw health for herds mostly kept in tie stalls. They did not report differences in effects of trimming between tie stalls and free stalls. Therefore, it can be speculated that regular trimming is important for good claw health and that different housing conditions may have different optimal trimming methods, but that the methods we applied did not differ substantially despite the initial change in pressure patterns after trimming.

The reasons why we did not find significant effects of trimming could be the limited size of the experimental groups or the short duration of the experiment. Still, predicted means of trimming methods for claw dimensions were not different for any of the measurements. Furthermore, differences between floor groups in claw dimensions were established within the same time frame. Thus, it is not expected that trimming effects would become significant with substantially larger experimental groups or a longer study period. Moreover, if cows were trimmed again at drying off, effects of the initial trimming would be obscured thereafter.

Supporting the results of Jungbluth et al. (2003) and Kremer et al. (2007), a significant difference between the floors appeared in mo 1 and 3 for sole hemorrhages. Nonetheless, an experimental study on the same floors (P. P. J. Van der Tol; unpublished data) did not reveal significant differences for sole hemorrhages. Similarly, Boyle et al. (2007) reported no effect of rubber flooring on hemorrhages. Differences between the latter study and our study might be explained in part by differences in rubber quality and rubber thickness. Most hemorrhages we observed were mild or small discolorations. In all treatment groups there was a marked decline in prevalence of hemorrhages in the first month of the experiment. The majority of hemorrhages present during the study may have had their origin in the period

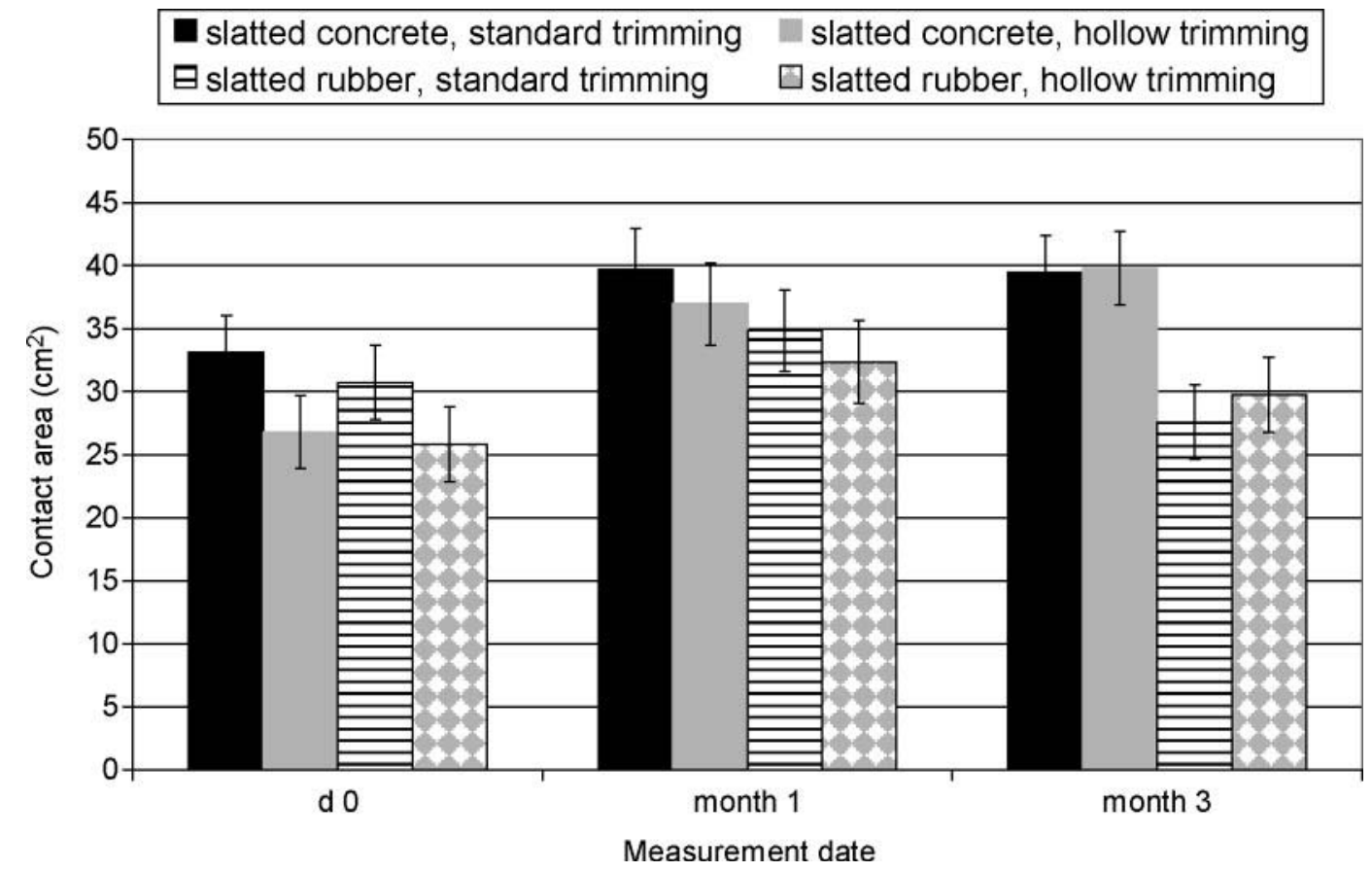

Figure 5. Predicted mean values $( \pm \mathrm{SE})$ for claw-floor contact area for treatment groups. 


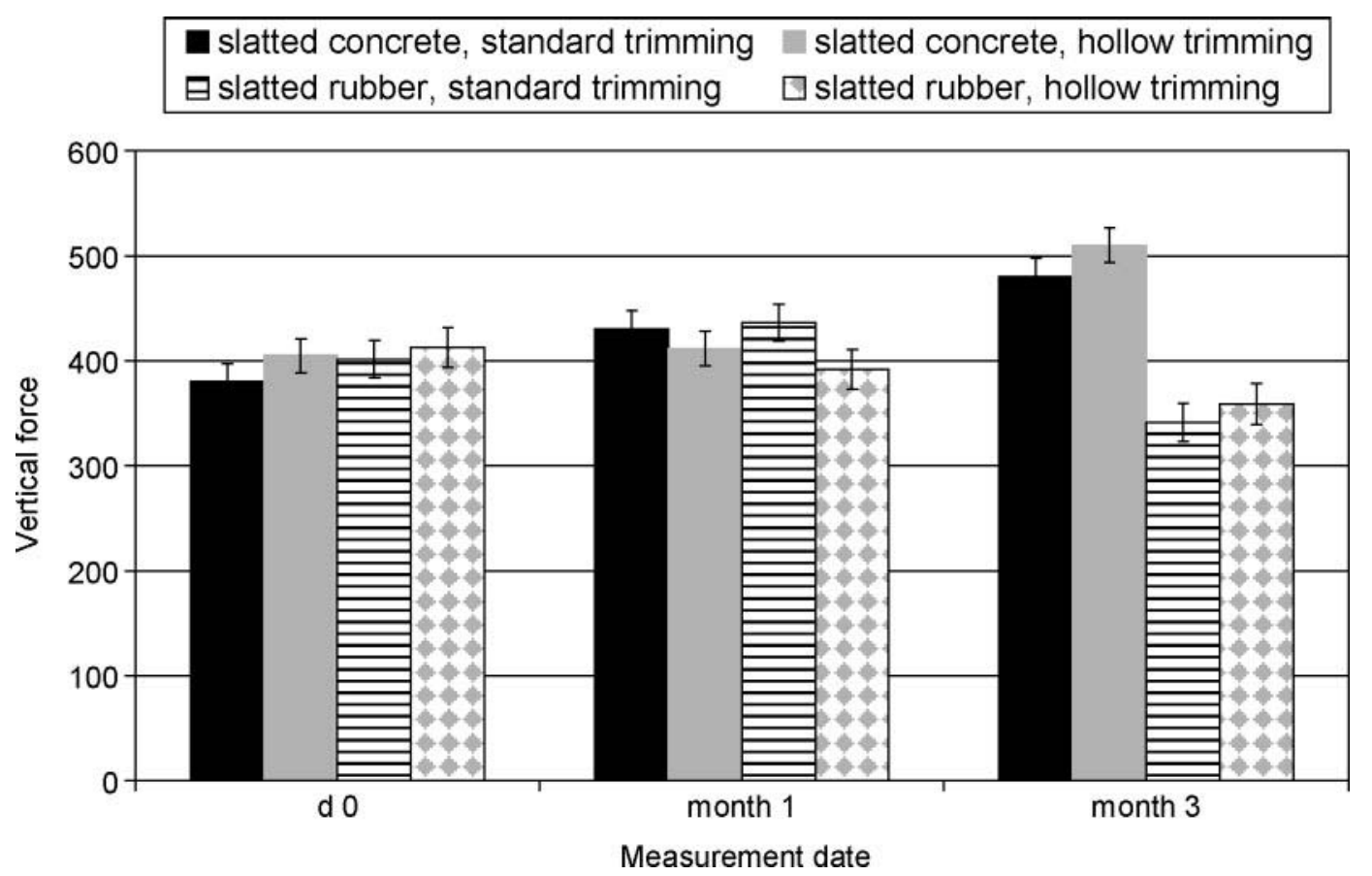

Figure 6. Predicted mean corrected values $( \pm \mathrm{SE})$ for vertical force for treatment groups.

before claws were trimmed. The greater reduction of sole hemorrhages found on soft floors could be due to a reduced mechanical load.

No differences between floors were found for the other claw disorders, in line with the results of Boyle et al. (2007), Kremer et al. (2007), and Vanegas et al. (2006). Although observer differences explained some variation, differences between the 3 experienced people who scored the lesions were small, and analysis without correction for observer differences yielded similar results. The significance of the lesion score at d 0 for scores obtained at mo 1 and 3 for both digital dermatitis and interdigital dermatitis illustrated the chronic character of these disorders. The significance of the interaction between floor and trimming method for digital dermatitis at mo 3 was probably influenced by initial differences in prevalence between treatment groups, as the predicted treatment means were similar to those at $\mathrm{d} 0$.

The results of this study regarding claw dimensions support earlier findings (Vanegas et al., 2006; Kremer et al., 2007; Telezhenko, 2007) with regard to flooring. Soft floors resulted in lower growth and wear and smaller claw angles, and cows on the SR floor had somewhat larger claws. Except for CAmean immediately after trimming, trimming method did not affect any of the claw shape measures until 3 mo later. The differences we found between lateral and medial claws agree with the results of Nuss and Paulus (2006), who also reported significantly larger size of lateral hind claws.
Similar to other studies (Vanegas et al., 2006; Kremer et al., 2007) we did not find significant differences between treatments in gait scores. The cows were filmed when they were forced to walk on a strip of concrete slatted floor outside of their home area. Thus, the gait scores obtained may not represent the voluntary locomotion of the animals on their home floors. Despite the absence of floor effects on gait scores, the IceTag data revealed less activity and less standing for cows on the SC floor. This supports the results of Kremer et al. (2007), but does not completely agree with results of Boyle et al. (2007). These authors reported similar standing times for cows on concrete and cows on rubber alley floors, but more standing in the free stalls for concrete floors. It is tempting to interpret the higher activity level on the SR floor as a sign of improved claw comfort, but it remains uncertain whether this finding coincided with better locomotion.

In line with the other measures, step traits revealed some effects of flooring but no effects of trimming. Patterns during the double-support phase were very similar for all treatments, however, and similar for the succeeding measurements. This indicated there were likely no subtle effects of treatments on step characteristics. Meyer et al. (2007) reported that trimming affected the area of first claw-floor contact for cows on a treadmill. Differences in CAmean between the 2 trimming methods disappeared quickly after trimming; this could explain the absence of effects of trimming on other measures. Compared with values reported by 
Telezhenko (2007) our values for CAmean are high. This is not expected to affect our results regarding treatment effects, because measurement sessions were balanced over treatments. The lower (corrected) Fmean for the SR floor and higher Fmean for the SC floor at the third measurement are remarkable. It would be expected that the larger CAmean, which is in agreement with results for claw dimensions, would result in lower values for Fmean for the SC floor. These results need to be treated with some caution.

\section{CONCLUSIONS}

The hypothesis that the alternative hollow trimming method is preferred over the standard Dutch method for cows on soft floors in a 3-mo time window was rejected. No interactions were found between flooring and trimming method, and none of the claw health or locomotion traits studied differed for the trimming methods. Cows on the rubber-topped floor had significantly fewer sole hemorrhages, spent more time standing, and had higher activity. Claw angles significantly decreased within 3 mo after trimming for all treatments, and claw dimensions generally increased. Cows developed larger claws with smaller angles and smaller claw-floor contact area on rubber-topped floors compared with concrete floors. Development of pressure patterns during the doublesupport phase time was similar for all treatments. Claw-floor contact area increased to a maximum in the first $30 \%$ of double-support phase time, remained more or less stable until $80 \%$ of double-support phase time, and sharply decreased as the leg pushed off.

\section{ACKNOWLEDGMENTS}

The support of the staff of research farm the Waiboerhoeve (especially Gerard de Bree and Jan van Dieren) is appreciated and we are indebted to Klaas Blanken and Sjieuwke Wind for their assistance with data collection, Johan van Riel for statistical analysis, and Piet Kloosterman for trimming instruction. The work was supported by RsScan International (Olen, Belgium) and was funded by the Dutch Ministry of Agriculture, Nature and Food Quality (LNV), research program Animal Welfare (P434).

\section{REFERENCES}

Boyle, L. A., J. F. Mee, and P. J. Kiernan. 2007. The effect of rubber versus concrete passageways in cubicle housing on claw health and reproduction of pluriparous dairy cows. Appl. Anim. Behav. Sci. 106:1-12.

Fjeldaas, T., A. M. Sogstad, and O. Østerås. 2006. Claw trimming routines in relation to claw lesions, claw shape and lameness in Norwegian dairy herds housed in tie stalls and free stalls. Prev. Vet. Med. 73:255-271.

Flower, F. C., A. M. de Passillé, D. M. Weary, D. J. Sanderson, and J. Rushen. 2007. Softer, higher friction flooring improves gait of cows with and without sole ulcers. J. Dairy Sci. 90:1235-1242.
Galindo, F., and D. M. Broom. 2002. Effects of lameness of on social and individual behaviour of dairy cows. J. Appl. Anim. Welf. Sci. 5:193-201.

Gilmour, A. R., B. J. Gogel, B. R. Cullis, and R. Thompson. 2006. ASREML User Guide Release 2.0. VSN International Ltd., Hemel Hempstead, UK.

Holzhauer, M. 2006. Claw health in dairy cows in the Netherlands. Epidemiological aspects of different claw disorders in dairy cattle in the Netherlands. PhD Thesis.Utrecht University, Utrecht, the Netherlands.

Holzhauer, M., C. J. M. Bartels, B. H. P. van den Borne, and G. van Schaik. 2006. Intra-class correlation attributable to claw trimmers scoring common hind claw disorders in Dutch dairy herds. Prev. Vet. Med. 75:47-55.

Jungbluth, T., B. Benz, and H. Wandel. 2003. Soft walking areas in loose housing systems for dairy cows. Pages 171-177 in Proc. 5th Int. Dairy Housing Conf., Fort Worth, TX. Am. Soc. Agric. Eng., St. Joseph, MI.

Kremer, P. V., S. Nueske, A. M. Scholz, and M. Foerster. 2007. Comparison of claw health and milk yield in dairy cows on elastic or concrete flooring. J. Dairy Sci. 90:4603-4611.

Manske, T., J. Hultgren, and C. Bergsten. 2002. The effect of claw trimming on the hoof health of Swedish dairy cattle. Prev. Vet. Med. 54:113-129.

Manson, F. J., and J. D. Leaver. 1988. The influence of concentrate amount on locomotion and clinical lameness in dairy cattle. Anim. Prod. 47:185-190.

Meyer, S.W, M.A. Weishaupt, and K.A. Nuss. 2007. Gait pattern of heifers before and after claw trimming: A high speed cinematographic study on a treadmill. J. Dairy Sci. 90:670-676.

Nuss, K., and N. Paulus. 2006. Measurements of claw dimensions in cows before and after functional trimming: A post mortem study. Vet. J. 172:284-292.

Rushen, J., and A. M. de Passillé. 2006. Effects of roughness and compressibility of flooring on cow locomotion. J. Dairy Sci. 89:2965-2972.

Sogstad, Å. M., T. Fjeldaas, O. Østerås, and K. Plym Forshell. 2005. Prevalence of claw lesions in Norwegian dairy cattle housed in tie stalls and free stalls. Prev. Vet. Med. 70:191-209.

Somers, J. G. C. J. 2004. Claw disorders and disturbed locomotion in dairy cows: The effect of floor systems and implications for animal welfare. $\mathrm{PhD}$ Thesis. Utrecht University, Utrecht, the Netherlands.

Somers, J. G. C. J., K. Frankena, E. N. Noordhuizen-Stassen, and J. H. M. Metz. 2003. Prevalence of claw disorders in Dutch dairy cows exposed to several floor systems. J. Dairy Sci. 86:2082-2093.

Somers, J. G. C. J., W. G. P. Schouten, K. Frankena, E. N. NoordhuizenStassen, and J. H. M. Metz. 2005. Development of claw traits and claw lesions in dairy cows kept on different Floor systems. J. Dairy Sci. 88:110-120.

Telezhenko, E. 2007. Effect of flooring system on locomotion comfort in dairy cows: Aspects of gait, preference and claw condition. $\mathrm{PhD}$ Thesis. Swedish University of Agricultural Sciences (SLU), Skara, Sweden.

Toussaint Raven, E. 1989. Cattle Foot Care and Claw Trimming. Farming Press, Ipswich, UK.

Tucker, C. B., D. M. Weary, A. M. de Passillé, B. Campbell, and J. Rushen. 2006. Flooring in front of the feed bunk affects feeding behavior and use of freestalls by dairy cows. J. Dairy Sci. 89:20652071.

Van der Tol, P. P. J. 2004. Biomechanical Aspects of the ClawFloor Interaction in Dairy Cattle: Implications for locomotion and claw disorders. PhD Thesis. Utrecht University, Utrecht, the Netherlands.

Van der Tol, P. P. J., S. S. van der Beek, J. H. M. Metz, E. N. Noordhuizen-Stassen, W. Back, C. R. Braam, and W. A. Weijs. 2004. The effect of preventive trimming on weight bearing and force balance on the claws of dairy cattle. J. Dairy Sci. 87:1732-1738.

Vanegas, J., M. Overton, S. L. Berry, and W. M. Sischo. 2006. Effect of rubber flooring on claw health in lactating dairy cows housed in free stall barns. J. Dairy Sci. 89:4251-4258. 